Sultan Qaboos University

\title{
A Folk Story from Dhofar A Pathway to Indigenous Knowledge
}

\begin{tabular}{c}
\hline Ali Tigani EIMahi \\
\hline Professor, Archeology Department \\
College of Arts \\
University of Khartoum
\end{tabular}

Ahmed Mohamed al Khatheri

Ministry of Agriculture

Sultanate of Oman 


\title{
A Folk Story from Dhofar \\ A Pathway to Indigenous Knowledge
}

Ali Tigani EIMahi and Ahmed Mohamed al Khatheri

\section{Abstract}

Folktales serve certain aspects and involve meaningful intentions in the society. This paper assess a Dhofari folk story in Oman. The story denotes the significance of folk explanation for the first emergence of poultry in Dhofar. It compares the beautiful coloured bird the Arabian partridge, Alectoris melanocephala in Dhofar's environment with the common domestic chicken Gallus domesticus. The paper concludes that the folktales target the conservation of the society's traditions, educating and enlightening the society's members especially the young generations and most all demonstrates the faculty of folk explanation. Therefore, the paper urges that these folktales must be documented and studied, since they represent a valuable key part in the Omani cultural heritage.

Keywords: Folktales, Dhofari folk story, the role of folktales, Dhofar region, Arabian partridge, Omani cultural heritage.

\section{قصة شعبية من ظفار:

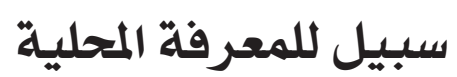

علي التجاني الماحي و محمد احمد الكثيري

\begin{abstract}
مستخلص

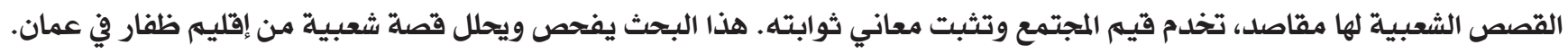

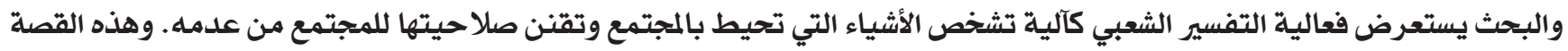

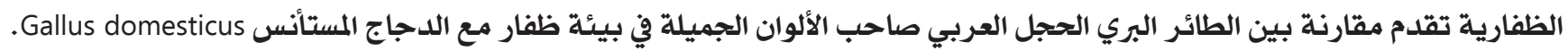

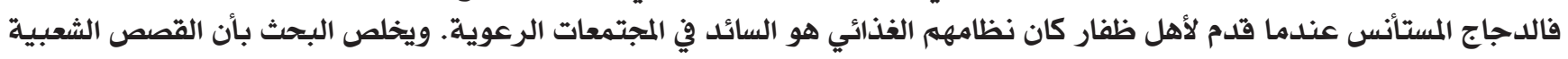

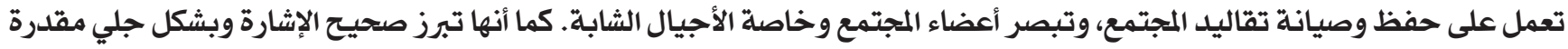

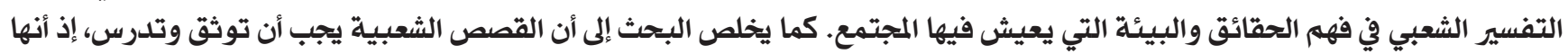
جزء هام ورئيس في التزات الثقافي العماني.
\end{abstract}

الكلمات الدالة: القصص الشعبية، دور القصص الشعبية، إقليه ظفار، التفسير الشعبي، الحجل العربي، التزاث الثقافي العماني. 


\section{Introduction}

Folktales are the lore of any given group of people or society. They are a social repository of knowledge, experience, learning and identity. They carry and express empirical experience, culture, and adaptation to environmental conditions. They also reflect a society's values, ethics, faith and strengths. Traditional narratives are communicated from one generation to another with clarity and captivating imagination. They are created and narrated to serve more than one purpose.

Folktales exert a tenacious grip over their audience irrespective of age or gender. The group assembled to hear and see the narrator forms a social assembly for entertainment. Back in distant past, hunter/gatherers must have sat around a fire narrating their daily experience in hunting animals and collecting esculent wild plants. Studies of contemporary hunter/gatherers show that their evenings are still spent in exchanging narratives of their daily experience and their ancestors (cf. Sinha 1972; Lee 1972; Price and Brown 1985; Ingold 1992; Bird-David and Bird 1997; etc.). This is how indigenous knowledge is accumulated, conserved, and passed from one generation to another. Humans are good at telling stories and all of us enjoy hearing them. It is part of socialization, entertainment and amusement. There seems to be a human psychological need to tell a tale, to be heard and, most of all, to capture an audience's attention. Humans are good at devoting their imagination and artistic talents to shaping stories, good at weaving facts with imagination. It is an oral tradition and usually committed to the generations' memory.

This paper examines a traditional folk tale from the Dhofar region of southern Oman, seeking to understand its methods and objectives.

\section{The story}

Two wild birds came down from the mountains to the coastal city of Salalah. They wanted to buy goods from the city market. On their way down from the mountainous land, they took a route known as «the way of the alhashkak» which is usually covered by dense forest. They reached the plains of «al jarbab» and then they arrived at the city after, passing an area known as «al daen» between the plains and the city limits.

Once they reached Salalah, they went straight to a family called «Neighbours». The tradition was that every pastoralist family in the mountains had a close relationship with a family in the city, a relationship mutually cherished. They would exchange visits and gifts and the city family usually spent the rainy season, the "Khareef» with their friends in the mountains.

When the two birds arrived at their neighbours' house, they began to list the items they need to buy at the market. But of course, markets are a male territory and females are not allowed to visit or shop there. So men from their neighbour's family did the required shopping on behalf of the visiting birds.

All the goods needed by the two birds were eventually packed and ready to be transported to the mountains. In the evening, and before they went to bed, one of the birds said to the other:

Now everything is ready. By the will of Allah, we will start our journey back to the mountain tomorrow.

The second bird said to her:

I'm going back to the mountains tomorrow without saying "By the will of Allah.»

Next morning, the bird which had said «By the will of Allah» embarked on her journey and made it to her home in the mountains. And today, she is seen as the ancestor of that beautiful wild bird the Arabian Partridge (Alectoris melanocephala) in the mountains of Dhofar (Figure 1 and 2). It is known to pastoralists as asuni.

The bird who had said I will go without saying «By the will of Allah" could not return to her home in the mountains. She remained in Salalah and became the predecessor of all the domestic fowl in the city. The chickens are her descendants. This is how the story ends.

The story's contents and indications

The circumstance and conditions surrounding the story's events indicate copious indigenous knowledge. However, it would be useful first to have a brief look at the story's geography.

The setting is Dhofar region of southern Oman. This is an ancient region characterized by exceptional greenery in this part of Arabia. Annually in July-September, the monsoon winds bring in misty clouds from the Arabian Sea and on reaching Dhofar's mountains; these rain-bearing clouds create the particular qualities and features of a rainy season known locally as the Khareef. This season covers Dhofar's coastal plains, its escarpment and high mountains grounds with lush greenery.

Climatic change occurred here after the Holocene ca. 10.000 BC with new conditions forcing early human movements from the Empty Quarter al Rab al Kaly, 
southwards into the area of Dhofar. Down to the present, Dhofar's mountains, hills and plains remain the territory of Dhofari pastoralists who comprise several tribal groups closely interlinked by marriage, kinship. Their spread across Dhofar is dictated by the seasonality and requirement of their key animals. Hence, they are either engaged in cyclic or in transhumant seasonal movements. However, there are also Dhofari settled pastoralists and indeed some who chose to live on the coast and take up fishing as a livelihood. Such settlements eventually grew through commerce and trade with their geographical location and products facilitating ancient human contact and interaction with other centers of civilization across both land and sea. Pastoralism is an old tradition in Dhofar and must have evolved at some time after the Holocene in 10.000 BC. It is a way of life, an adaptation and a culture. Folktales are a brilliant thread within a rich cultural fabric. The narrative here reflects the region specific environmental characteristics, seasonal change and the adaptation of inhabitants to both the mountains and coastal area. It presents Dhofar's landscape vividly intermingled with human territoriality and adaptation.

\section{The art of personification}

This is an imaginary story, but it relates significantly to existing real life in Dhofar and displays this precisely. The birds are personified as two women from the pastoral groups that inhabit the mountains. It is an attractive agreeable personification.

Indeed the story's opening suggests immediately that the women must have been cattle pastoralists. This is indicated by the fact that both the city and mountain families exchange visits and consider each other as «neighbours». Moreover, Dhofari cattle herders have permanent settlement sites unlike the areas of nomadic camel and goat pastoralists whose sites are ephemeral.

The personification serves a crucial objective. Auditors, and especially the children are engaged in an exercise of the imagination. While listening to the story's events, they spontaneously draw images of the characters, the background of the events and the dynamics of the episodes. Listening to such narratives fashions creative power in children, which can be outlined follows:

First, children create new images and concepts by relating the experiences of other people to their own experience and knowledge.

Second, it also grooms their ability to create mental images of what has never actually been experienced or taken place in their real lives. In a way it is a challenge that tests their abilities.

Third, this is a very useful exercise for developing children's power to form and portray mental images of what is not actually present but only reported and heard.

\section{Human interactions}

The story reveals human contact around mutual interests. The interaction is both social and commercial, and the narrative clearly reveals this. It is the link of two diverse adaptations: the pastoralists and settlers along the coasts of Dhofar. Also, blood ties and bonds by marriage exist between the two groups. It is well known that some pastoralists for one reason or another have abandoned animal herding and opted for an urban business. Hence, it is no surprise that kins and acquaintances are usually found in these two parts of the Dhofar region.

Furthermore, this interaction sustains a complementary relationship that brings both groups together. In their mutual needs and provisions, the pastoralists require particular commodities such as sugar, tea, coffee, grains, dates, dry sardines, cloth material, etc. On the other hand, the urban settlers require pastoral products such as animals, hides, ghee, etc. This reciprocal arrangement is maintained and consolidated by human contact. It is also manifested by the name each family (in the city or mountains) gives to the other: «neighbours». All human cultures, religions and traditions see a neighbour as a subject of attention and respect. Therefore, the material needs of each group are merged into a close human bond of neighbourliness.

Furthermore, the story defines the demarcation of the region into mountain, plains and coast mentioning the limits and boundaries of each area. In fact, the setting of the story is Jabal al Gara, which is characterized by six ecological zones and described by Miller and Morris (1988) as in Fig 1

.The coastal plains

.The foothills

.Escarpment woods and grasslands

.al Khatum

.al Quatan

.al Najd

These zones are differentiated on the basis of the availability of certain plant species and topographic physical characteristics. Their flora is characterized by 
a wide variety of trees, deciduous stemmed bushes, and shrubs. The story describes precisely the two birds' journey throughout these ecological habitats:

They took a passage known as "the way of the alhashkak» which is usually covered by dense trees. They followed their trip to come the plains «aljarbab» and they reached the city after passing an area known as «aldaen» between the plains and the city's limits.

In a sense, the story portrays the environmental setting and the ecological zones of Jabal al Gara. Consequently, this reflects a general awareness of the habitat and most of all the tribal territoriality in this ecoregion. It delineates how the inhabitants comprehend the landscape, its floral conditions and tribal territory.

\section{The story's objectives and goals}

At a time when there were no other means of social entertainment, folk stories were intended for entertainment for different age and gender groups. But such narratives normally involve other significant intentions. They target the conservation of the society's traditions, educating and enlightening the society's members especially the young generations. The listeners were usually captivated by such envisioned narratives. The most amusing and the best stories were usually committed to memory and remembered over the years.

Conserving traditions leads to preserving culture and recording the gradual change in the society's behaviour, ways and methods of adapting to prevailing environmental conditions. It testifies to their survival and existence in a specific habitation. But most of all, it is the conservation of their culture and identity. It is known that traditional groups, and especially pastoralists, do not yearn for change. They value their way of life and culture and strongly believe they lie at the heart of their identity.

\section{Folk explanation}

One of the most effective cultural processes in any given society is "the folk explanation». In fact, this was "science» before modern science developed. Moreover, accumulated empirical knowledge and experience eventually became the seedbed of modern science. At present, despite the advance of science, many societies are still influenced by the sway of folk explanation.

Man has long attempted to identify and explain everything around him in his environment. Significantly, man even named the stars at a time when his knowl- edge about the cosmos was very limited. It is folk explanation which still identifies and explains the reasons for diverse occurrences of various elements and phenomena. It is a tool that creates and establishes images and values of everything in a society's environment. It is an ancient tool of explaining everything.

In essence, then, this story is a folk explanation for the first emergence of poultry in Dhofar. Unfortunately, the history of the introduction of this common domestic bird Gallus domesticus into Dhofar is not known. Elderly informants confirm that this bird is unclean because it eats filth and human and animal excrement. They also confirm that pastoralists never ate this bird and it was only after the Eighties that the younger generation started to include it in their diet. Up to the present, the Dhofari pastoralists do not keep or have poultry in their settlement.

It is known that traditional Dhofari pastoralists, like all pastoralists, are proud of their pastoral diet. The introduction of chicken as a bird that scavenges, eating refuse and decaying organic matter in the houses and street must have appalled them. Therefore, the story arises to explain how the society regards this particular bird and how it came to be around. It classifies the bird and explains why society rejects it.

It also stresses the significance of belief in Allah and His will manifested in all creatures and events. Such religious elucidation enhances the story and strengthens faith in God. It shows a righteous attitude every member of the society should endorse. The story through birds shows a woman involved in faith and worthy action and another one whose action implies a lack of belief. This erroneous woman is marked disgracefully. There is also another issue. The story successfully identified the chicken as taboo: no one should eat it. This is how folk explanation shapes the taboos of the society and uses a story as a vehicle conveying messages to its members. Taboos are designed and endorsed by folk explanations, which serve here as a pragmatic explanation for the benefit and the welfare of the society (cf. EIMahi 1994).

Furthermore, the story uses folk explanation to emphasize the presence of another bird which explicitly submits to the will of Allah in her intentions and deeds. This again confirms and advocates the significance of religious conviction. It is society's faith which is made manifest in the climax of the story.

This story, therefore conveniently performs a specific task through folk explanation. It explains the presence of the beautiful and coloured bird the Arabian partridge, Alectoris melanocephala (Fig. 3). People 
are fond of this wild bird. Indeed, the different Dhofari pastoral groups have known it from very early times. It is an integral part of their habitat and ecosystem (Fig. 2 and 3).Dhofar is one of three regions in the world beside Southern Yemen and Saudi Arabia that are home to this bird (cf. Johnsgard 1988; Hayes 1995 and Madge and McGowan 2002). Current information about this bird is very limited and as it has been described by ElMahi (forthcoming) as an «information void». He (ibid.) argues that this bird needs to be studied in detail since it is part of the natural heritage of Oman.

With this story, Dhofari pastoralists endeavored to conserve their ways, culture, identity and a particular species in their environment. Surprisingly, this simple folk story has effectively stirred the status of the Arabian partridge, Alectoris melanocephala which has not been addressed by the present various scientific research centers in the Sultanate (cf. ElMahi forthcoming).

Finally, folk stories are vanishing in the face of modernization, which is modifying all aspects of life. It brings with it education, which eradicates all that is traditional. Irrespective of what traditional advocates, education removes it from practice and dismisses it. Therefore, folk stories must be documented and studied, since they represent a crucial part of the Omani cultural heritage.

\section{References}

1. Bird-David, N. and R.L. Bliege Bird,1997, The science of foragers: evaluating variability among hunter-gatherers. Antiquity 71: 477-480.

2. EIMahi, A.T., 1994, Traditional wildlife conservation: A vanishing tribal lore in the Sudan. in Indigenous knowledge for sustainable development in the Sudan.Sudan Library series, Institute of African and Asian Studies. Khartoum.

3. ElMahi (forthcoming) The Arabian partridge Alectoris melanocephala in Dhofar: To be or not to be.

4. Hayes, L.B., 1995, Upland Game Birds: Their breeding and Care. Leland Hayes, Valley Center, CA.

5. Ingold, T., 1992, Foraging for data, camping with theories: Hunter-gatherers and nomadic pastoralists in archaeology and anthropology. Antiquity 66: pp.790-803.

6. Johnsgard, P.A., 1988. The Quails, Partridges and Francolins of the world. Oxford University press, Oxford, UK.

7. Lee, R. B., 1972, Hunters and Gatherers Today (ed.) M.G. Bicchieri, pp. 327- 368 Holt, Reinrhart \& Winston, INC. New York.

8. Madge, S., McGowan,P. 2002. Pheasants, Partridges, and Grouse. Princeton University Press, Princeton, NJ.

9. Miller, A. G. and Morris, M. 1988 Plants of Dhofar The southern region of Oman Traditional, economic and Medical uses, The Office of the Adviser for Conservation of the Environment, Diwan of Royal Court Sultanate of Oman.

10. Price, T. D., and Brown, J. A., 1985, Aspects of Hunter-gatherer complexity. In Prehistoric hunter-gatherers: The emergence of cultural complexity, edit T.D. Price and J.A. Brown, pp. 3-20. Academic Press. New York.

11. Sinha, D .P. 1972 The Birhors. Hunters and Gatherers Today (ed.) M.G. Bicchieri, pp 371-403, Holt, Reinhart \& Winston, Inc. New York. 


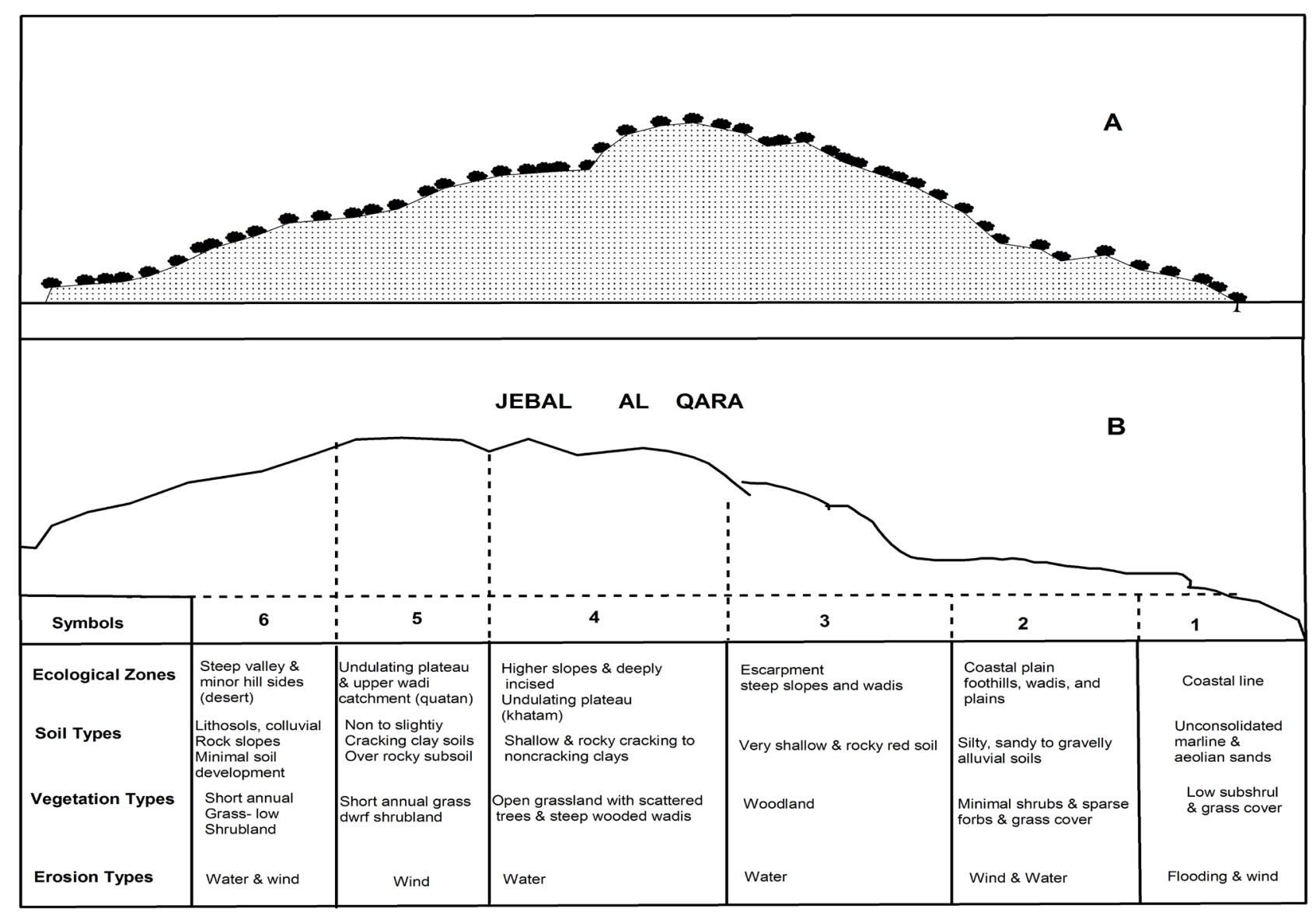

Figure.1. The Ecological zones of Jabl al Gara (Miller and Morris 1988).

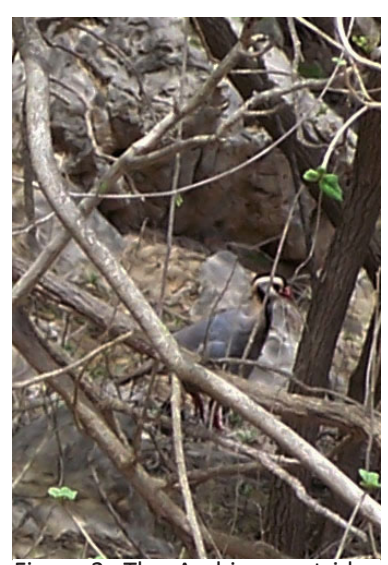

Figure.2. The Arabian partridge (Alectoris melanocephala) in Dhofar.

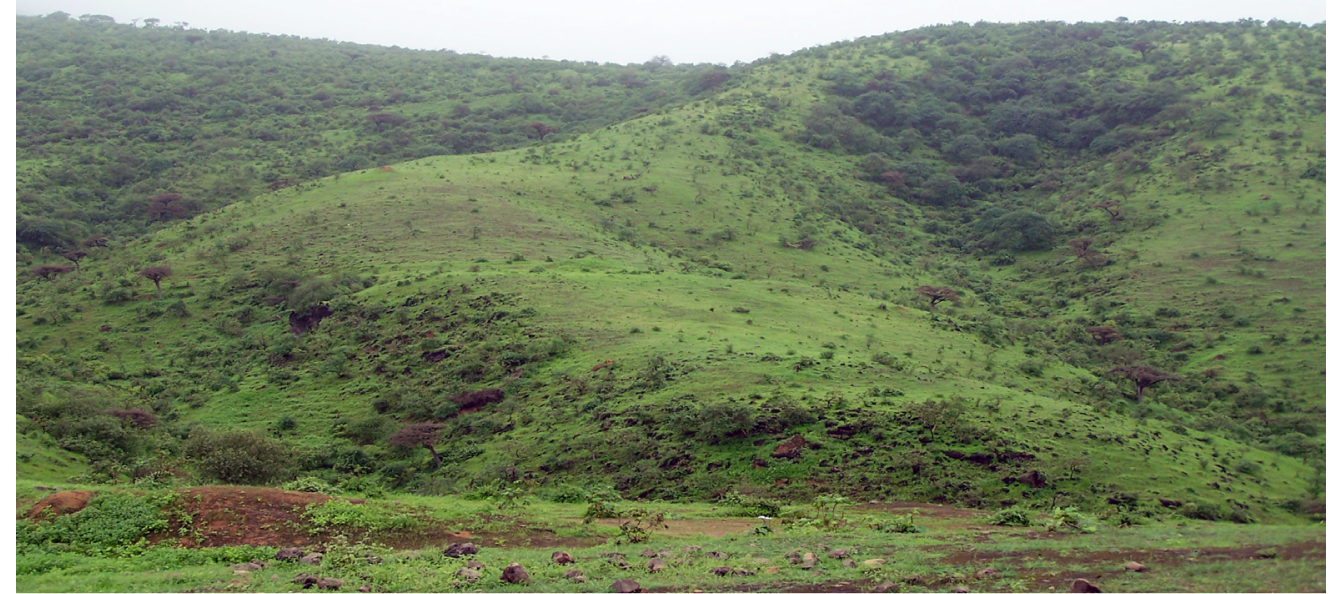

Figure.3. The habitat of the Arabian partridge. 
